\title{
The upscaling of transpiration from individual trees to areal transpiration in tree belts
}

\author{
Russell S. Crosbie • Brett Wilson • \\ Justin D. Hughes • Christopher McCulloch
}

Published online: 9 October 2007

(C) Springer Science + Business Media B.V. 2007

\begin{abstract}
Sap flow measurements have long been used to measure transpiration in individual trees and there exist some well established methods for upscaling individual tree volumetric transpiration to areal transpiration in plantation and forest plots. However, where edge effects are significant, such as in tree belts, the area the volumetric transpiration is to be projected upon is unknown. This paper provides a methodology for estimating the area that a tree belt hydrologically occupies by using either measurements of tree root density or soil moisture distribution. An application of the proposed methodology shows that simply assuming that the area of the tree belt is the
\end{abstract}

The online version of the original article can be found at http:// dx.doi.org/10.1007/s11104-007-9337-y.

Responsible Editor: Yan Li.

R. S. Crosbie $(\bowtie)$

CSIRO Land and Water, PMB 2,

Glen Osmond, SA 5064, Australia

e-mail: russell.crosbie@csiro.au

B. Wilson · J. D. Hughes $\cdot$ C. McCulloch

Orange Agricultural Institute,

Forest Rd, Orange, NSW 2800, Australia

B. Wilson

e-mail: brett.wilson@dpi.nsw.gov.au

J. D. Hughes

e-mail: justin.hughes@dpi.nsw.gov.au

C. McCulloch

e-mail: chris.mcculloch@dpi.nsw.gov.au crown projected area could lead to an overestimation of the areal transpiration of $100 \%$.

Keywords Sap flow - Transpiration · Tree belts . Upscaling

Erratum to: Plant Soil (2007) 297:223-232

DOI 10.1007/s11104-007-9337-y

This article was erroneously published in Vol 297.

\section{Introduction}

Inferring tree water use from sap flow velocities has a long history (Huber 1932) and there are many examples in the literature of the use of the technique in many different environments and in different tree species. To be useful in studies of catchment water balance, the individual tree water use volumes need to be scaled on an areal basis so that they can be compared to other water fluxes measured on an areal basis such as rainfall and evapotranspiration from micro-meteorological techniques. To avoid any confusion in this paper, volumetric transpiration refers to a volume of water transpired per unit time, (e.g. 1 day $^{-1}$ ), and areal transpiration refers to a volume of water transpired per unit of area and time, (e.g. $1 \mathrm{~m}^{-2}$ day $^{-1}$ or $\mathrm{mm} \mathrm{day}^{-1}$ ). 
In its simplest form, the areal transpiration is the average volumetric transpiration per stem $\left(1 \mathrm{stem}^{-1-}\right.$ day $^{-1}$ ) multiplied by the planting density ( for a monoculture plantation of regularly spaced equal aged stems (Hatton and Vertessy 1990). Areal transpiration becomes more difficult to determine for more complex systems, such as a natural forest consisting of different sized trees of different species (Zeppel et al. 2006). There are many reviews on the topic of scaling water use from tree to stand, e.g. Hatton and $\mathrm{Wu}$ (1995), Granier et al. (1996) and Cermak et al. (2004). However, most studies were not designed to address the effects of edges on vegetation water use and so the work was conducted well away from the edges of plantation blocks or forests.

In studies of isolated trees the areal transpiration is often calculated as the volumetric tree water use divided by the crown projected area (Cermák et al. 2000; David et al. 2004). Again this method does not incorporate the edge effects.

In some tree planting configurations, edge effects apply to all trees. These layouts include windbreaks, hedgerows, tree belts and alley cropping systems. There are comparatively few examples in the literature of studies that have upscaled sap flow measurements from tree to tree belt. Due to edge effects, the area occupied hydrologically by the tree belt is uncertain and so upscaling is difficult. Previous studies have presented a range of solutions to this problem. In an alley cropping arrangement, the areal transpiration has been expressed as the volumetric tree water use per crown projected area (Lefroy et al. 2001; White et al. 2002), as an alternative Lefroy et al. (2001) upscaled transpiration over the whole tree/pasture plot. Wildy et al. (2004) defined a 'unit tree' which involved a water balance of the tree belt / pasture system in three sections up to $15 \mathrm{~m}$ from the centreline of the tree belt. None of these approaches has considered the areal transpiration in a way that allows the transpiration to be adequately used directly in a one dimensional water balance.

This paper presents a methodology for upscaling transpiration from tree to tree belt that incorporates an explicit consideration of the area hydrologically occupied by the tree belt. The 'effective width' methodology, described here, differs from previous approaches because it incorporates a consideration of the area outside of the crown area that the tree belt exploits for resources (water).

\section{Theoretical development of methodology}

In order to upscale the sap flow measurements from volumetric water use to areal transpiration, the ground area that the tree occupies needs to be known. At the ground surface (the area the water use is projected upon) the area of the tree is the stem. Below-ground, the area occupied by the tree is the roots; it is where water is collected from. Above-ground, the area occupied by the tree is the crown; it is where the tree intercepts light. Each of these three areas could be considered representative of the area of the tree in their own way, however, each will give vastly different areal transpiration rates for the same volumetric water use. The critical question here is: what is the area of ground surface that is completely hydrologically occupied by the tree? (Eagleson 1982; Ellis et al. 2005)

\section{Above-ground considerations}

White et al. (2002) used the crown projected area as the basis for the upscaling of tree water use to areal transpiration on the justification that this was the "ground area over which energy was absorbed by the trees." The ground area over which the tree belt is intercepting light can be seen as the area of the shadow cast by the tree belt. Depending upon the latitude, time of day and the orientation of the tree belt, this can be many times the crown projected area (Monteith 1973).

Net radiation from the sun is a key driver of evapotranspiration and so it follows that the shape of the curve of daily water use for well watered vegetation should track that of net radiation. A comparison of the patterns of water use throughout a day between a pasture and tree belt are informative, even though the units are not directly comparable (Fig. 1). The pasture trace follows a sine curve almost perfectly while the tree trace is steeper in the morning and afternoon and flatter during the middle of the day. This observation is consistent with the findings of Smith et al. (1997) who measured the net radiation intercepted by a tree belt using an array of net radiometers encircling the tree belt canopy. The patterns measured for net radiation in a tree belt and an adjacent crop were very similar to that shown in Fig. 1 for water use of a tree and an adjacent pasture. 


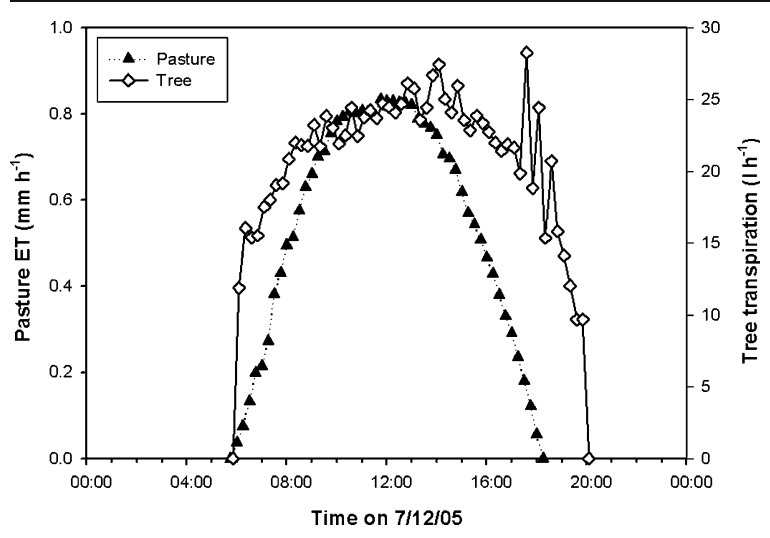

Fig. 1 A comparison of the daily cycle of water use by a pasture and adjoining tree belt

Due to being a three dimensional shape, rather than a flat plane, the tree belt intercepts more light than the pasture and therefore has more energy available for transpiration. A tree belt can also have an additional source of energy in the form of advection and entrainment of sensible heat (Taylor et al. 2001). These additional sources of energy suggest that a tree belt may not be limited to potential evapotranspiration (Smith et al. 1992) as calculated for a well adjusted flat plane (such as a homogeneous pasture or tree plantation).

Below-ground considerations

Although trees are said to be deep rooted, the majority of their roots are still likely to be close to the soil surface (Schenk and Jackson 2002). In a plantation or forest the proximity of a tree root to a stem is no indicator that the root belongs to that stem (Knight 1999). Due to the overlapping of root systems the root density is assumed to be homogenous in a horizontal direction and decrease with depth. A negative exponential relationship has been used to describe the root density $(R)$ distribution with depth $(z$; Gerwitz and Page 1974; Eastham and Rose 1990):

$R(z)=a e^{-b z}$

where $a$ and $b$ are fitting parameters. Landsberg and McMurtrie (1984) extended Eq. 1 to model root density distribution with depth and radial distance from the stems of isolated trees. It follows that a negative exponential function can also be used to describe the lateral spread of tree root density from a tree belt (Landsberg 1999; Sudmeyer 2002).
Sampling the root density distribution of a tree belt is costly, labour intensive and destructive (Knight 1999). To enable the changes through time to be seen a non-destructive means of obtaining a root density distribution needs to be found. There are several geophysical techniques (such as ground penetrating radar and differential electric conductance) that can be used for this task (Nadezhdina and Cermak 2003). However, as soil moisture content has been found to be negatively correlated with root density (Sudmeyer 2002), it provides an appropriate surrogate that can be easily measured on a routine basis.

\section{Mathematical formulation}

The hydrological influence of a tree belt decreases exponentially away from the tree belt to a point where there is no influence upon the adjoining pasture (Walker and Dowling 1991). This creates three zones: tree belt; mixed zone; and, pasture zone. Upscaling volumetric tree water use to areal transpiration requires that the mixed zone be eliminated and the tree/pasture system be reduced to a binary state. Reduction of this complex system to a binary state has been done previously for investigations of tree-crop interactions in a no-yield zone (Stirzaker et al. 2002; Oliver et al. 2005) and a no-recharge zone (Ellis et al. 2005).

The curve shown in Fig. 2 represents the influence (y) of the tree decreasing with distance $(x)$ from the tree. To reduce this system to a binary state an equivalent width (w) needs to be found such that the

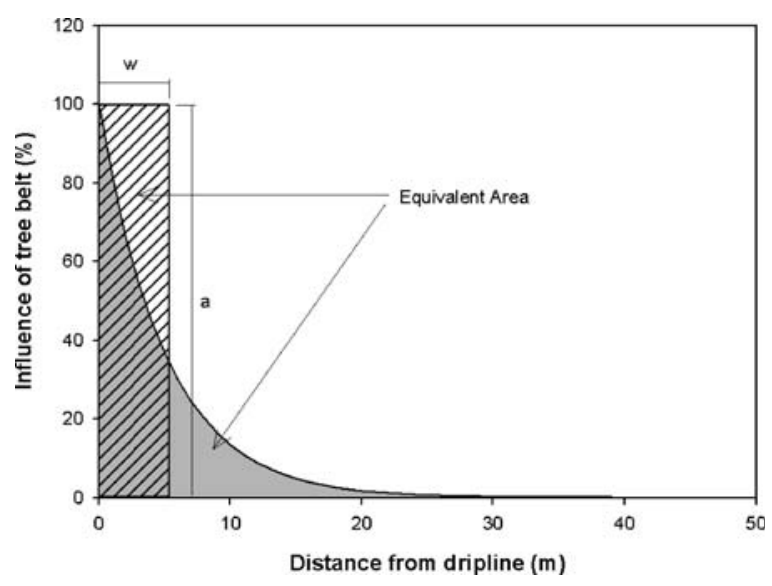

Fig. 2 Influence of tree belt decreases exponentially away from tree belt. The hatched rectangle has the same area as shaded below the curve in grey. If an equivalent area is calculated then an equivalent width $(w)$ can be derived 
area shaded in grey is equal to the hatched area. The curve is defined as:

$y=a e^{-b x}$

Where $a$ and $b$ are fitting parameters. The area under the curve is:

$\int_{0}^{\infty} y d x=\int_{0}^{\infty} a e^{-b z} d x=\frac{a}{b}$

The equivalent area is:

$a w=\frac{a}{b}$

$\therefore w=\frac{1}{b}$

From soil moisture measurements or root density observations the parameters $a$ and $b$ can be fitted to Eq. 2 and subsequently $w$ can be calculated.

As an extension of this methodology the calculations can also be used if the lateral extent of the roots can be estimated. For example, the lateral extent of the roots of belts of trees maybe twice the height (h) of the trees (Sudmeyer 2002). The height of the tree belt is much easier to measure than root density distributions or soil moisture distributions. If Eq. 2 is rearranged to solve for $b$ and then substituted into Eq. 5 then the result is:

$w=\frac{-x}{\operatorname{In} \frac{y}{a}}$

Since Eq. 2 asymptotes towards 0 as $x$ approaches infinity a limit needs to be imposed to enable these calculations to be done. If $y=5 \%$ is taken to be the limit and if it is assumed that $x=2 h$ then an approximate solution for the equivalent width can be calculated from Eq. 6:

$w \approx \frac{2}{3} h$

As the tree belt is assumed symmetrical, the equivalent width $(w)$ needs to be doubled and then added to the actual width of the tree belt to get the effective width for upscaling purposes. The effective width is then multiplied by the length of the tree belt to get the area that the tree belt occupies.
It is then a trivial process to divide the volumetric transpiration of the tree belt by the effective area to get the areal transpiration of the tree belt.

\section{Application of methodology}

Field site

In an agricultural catchment in the Central West of NSW, Australia (Brays Flat $33^{\circ} 04^{\prime} \mathrm{S}, 148^{\circ} 36^{\prime} \mathrm{E}$ ), tree belts were established 14 years ago. From a catchment hydrology perspective the areal transpiration of these tree belts was of interest. The site has a moreor-less equi-seasonal rainfall with an average of $630 \mathrm{~mm} \mathrm{year}^{-1}$ and an estimated annual pan evaporation of 1,580 mm year ${ }^{-1}$ (Jeffrey et al. 2001).

The two tree belts differed in their local hydrology. One tree belt was situated on a ridge and it was assumed that it did not access groundwater which was $12 \mathrm{~m}$ below ground level. We have labelled this tree belt the 'recharge tree belt'. The other tree belt was located in a groundwater discharge zone and it was assumed that the tree belt had access to groundwater at $1 \mathrm{~m}$ below ground level. We have labelled this tree belt the 'discharge tree belt'. Both tree belts consisted of three rows of trees, the discharge tree belt consisted mainly of Casuarina cunninghamiana Miq. and the recharge tree belt was a mixture of C. cunninghamiana and Acacia mearnsii De Wild.

\section{Volumetric transpiration}

Sap flow velocity was measured in six trees in each tree belt; each instrumented tree had four Greenspan SF300 sap flow probes. This gave 24 measurement points per tree belt. The corrected sap flow velocity (Swanson and Whitfield 1981; Edwards and Warwick 1984) was averaged for each tree and then averaged again by species for each tree belt. This resulted in an average daily corrected sap flow velocity for the $C$. cunninghamiana in the discharge tree belt and an average daily corrected sap flow velocity for both the A. mearnsii and C. cunninghamiana in the recharge tree belt (Fig. 3).

A length of tree belt was chosen to survey for the size and distribution of trees within each tree belt. All trees within the survey length had their species and circumference recorded twice during the measurement 
Fig. 3 Average daily corrected sap flow velocity for the $C$. cunninghamiana in the discharge tree belt and the A. mearnsii and C. cunninghamiana in the recharge tree belt
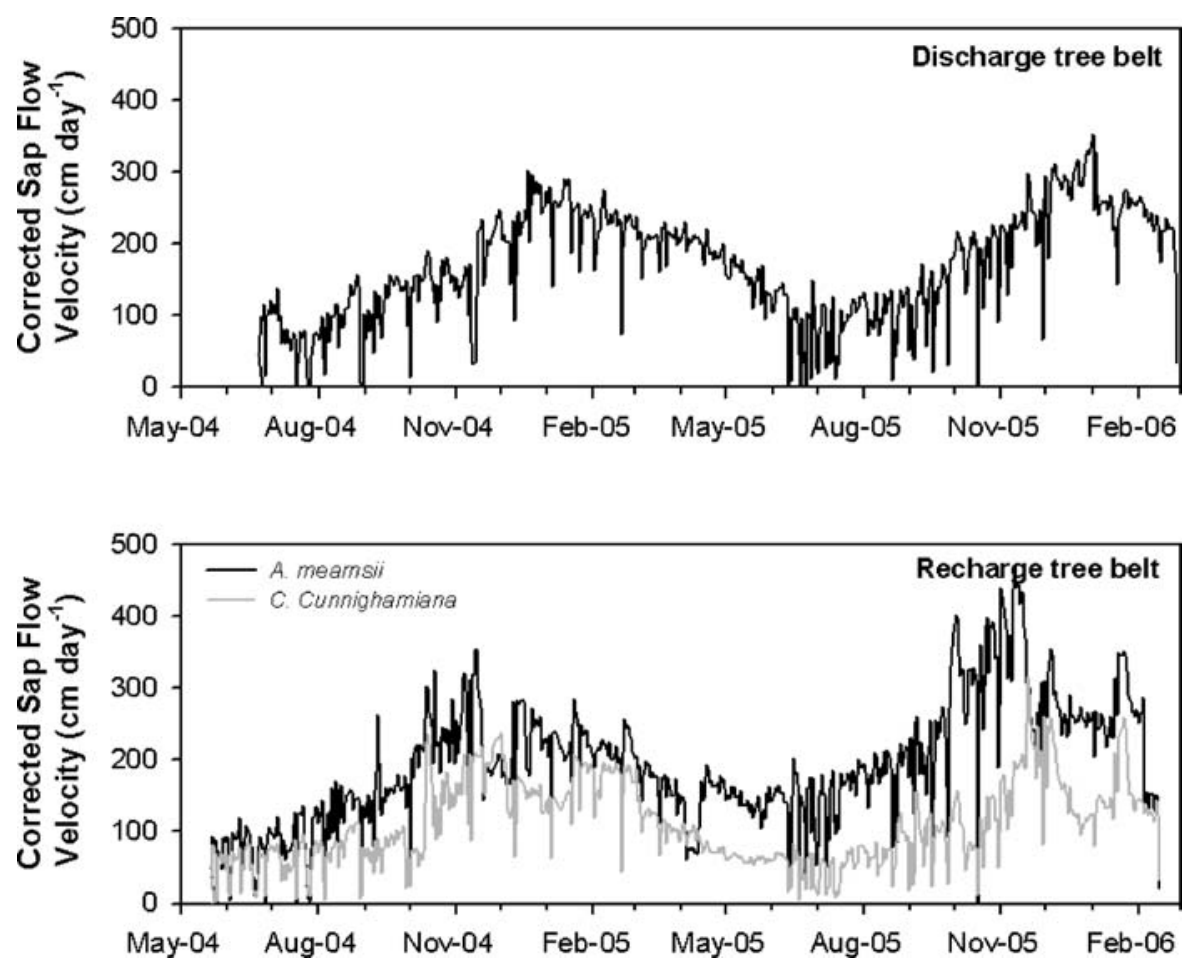

period. A subset of these trees had a core drilled to enable a relationship to be developed between sap wood area and circumference (Fig. 4). This relationship was used to determine the total area of sap wood in the survey length of tree belt.

A survey length of $49.0 \mathrm{~m}$ was chosen for the recharge tree belt and $27.6 \mathrm{~m}$ for the discharge tree belt. In the recharge tree belt there were 19 C. cunninghamiana trees with $1,945 \mathrm{~cm}^{2}$ of sap wood area in Jan 05 and $3,303 \mathrm{~cm}^{2}$ of sap wood area in Feb 06 , seven $A$. mearnsii trees with $3,018 \mathrm{~cm}^{2}$ of sap wood area in Jan 05 and $4,140 \mathrm{~cm}^{2}$ of sap wood area in Feb 06 and three other trees with a sap wood area of $145 \mathrm{~cm}^{2}$ in Jan 05 and $187 \mathrm{~cm}^{2}$ in Feb 06. In the discharge tree belt there were $71 \mathrm{C}$. cunninghamiana trees with $8,645 \mathrm{~cm}^{2}$ of sap wood area in Jan 05 and $12,191 \mathrm{~cm}^{2}$ of sap wood area in Feb 06 and six other trees with $810 \mathrm{~cm}^{2}$ of sap wood area in Jan 05 and $1,043 \mathrm{~cm}^{2}$ in Feb 06. There were many more trees in the discharge tree belt than originally planted due to recruitment of new trees.

The total sap wood area of the surveyed length of tree belts were estimated at two points in time and then linearly interpolated to enable an estimate of the sap wood area for each day of the measurement period. The sap wood area multiplied by the corrected sap flow velocity (Fig. 3) gives the volumetric transpiration for the surveyed length of tree belt (Fig. 5).

Equivalent width from soil moisture measurements

Soil moisture was measured in three replicate transects perpendicular to each of the tree belts using a neutron moisture meter (NMM). At the recharge tree belt site, $6 \mathrm{~m}$ deep NMM access tubes were installed

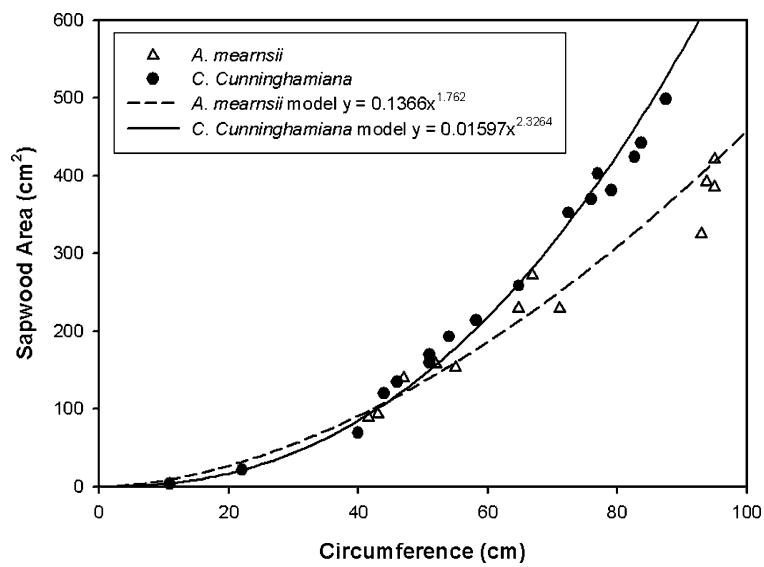

Fig. 4 Relationships developed between sap wood area and circumference from sap wood cores drilled from a selection of trees 
Fig. 5 Volumetric transpiration for 49.0 lineal $\mathrm{m}$ of recharge tree belt and 27.6 lineal $\mathrm{m}$ of discharge tree belt
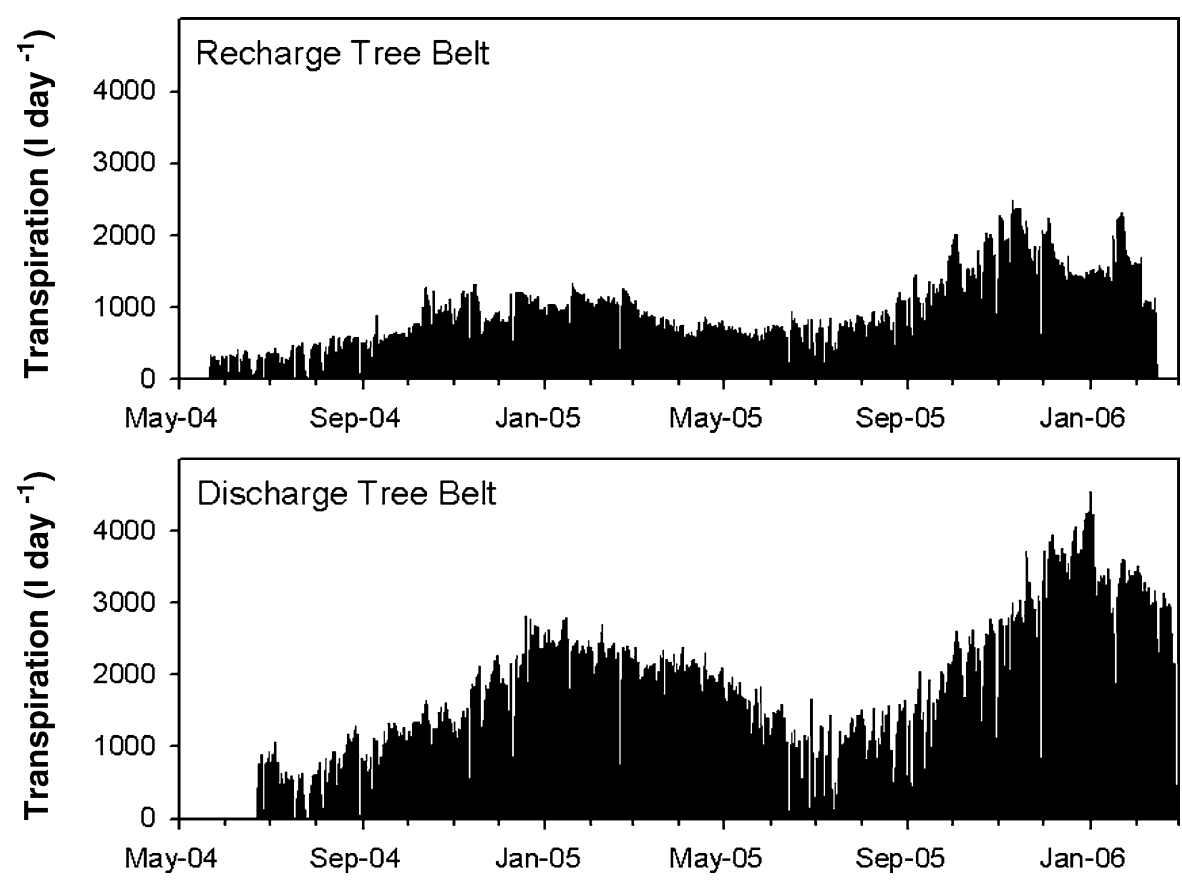

at $-2,0,5,15$ and $30 \mathrm{~m}$ relative to the dripline of the trees. The dripline refers to a line on the ground representing the edge of the crown. At the recharge tree belt site, $3 \mathrm{~m}$ deep NMM access tubes were installed at 0,5 and $15 \mathrm{~m}$ relative to the dripline of the trees. All NMM access tubes were monitored fortnightly at $20 \mathrm{~cm}$ depth increments.
The stored soil moisture, at both the recharge and discharge tree belts, increased with perpendicular distance away from the dripline (Fig. 6 and 7). At the recharge tree belt the stored soil moisture between tree stems $(-2 \mathrm{~m})$ and at the dripline $(0 \mathrm{~m})$ were not significantly $(P>0.05)$ different. The measurements at 15 and $30 \mathrm{~m}$ from the dripline were also not
Fig. 6 Stored soil moisture in profile at the recharge tree belt site measured in a transect perpendicular to the tree belt. Data is displayed as the mean of three replicates at each distance from the dripline

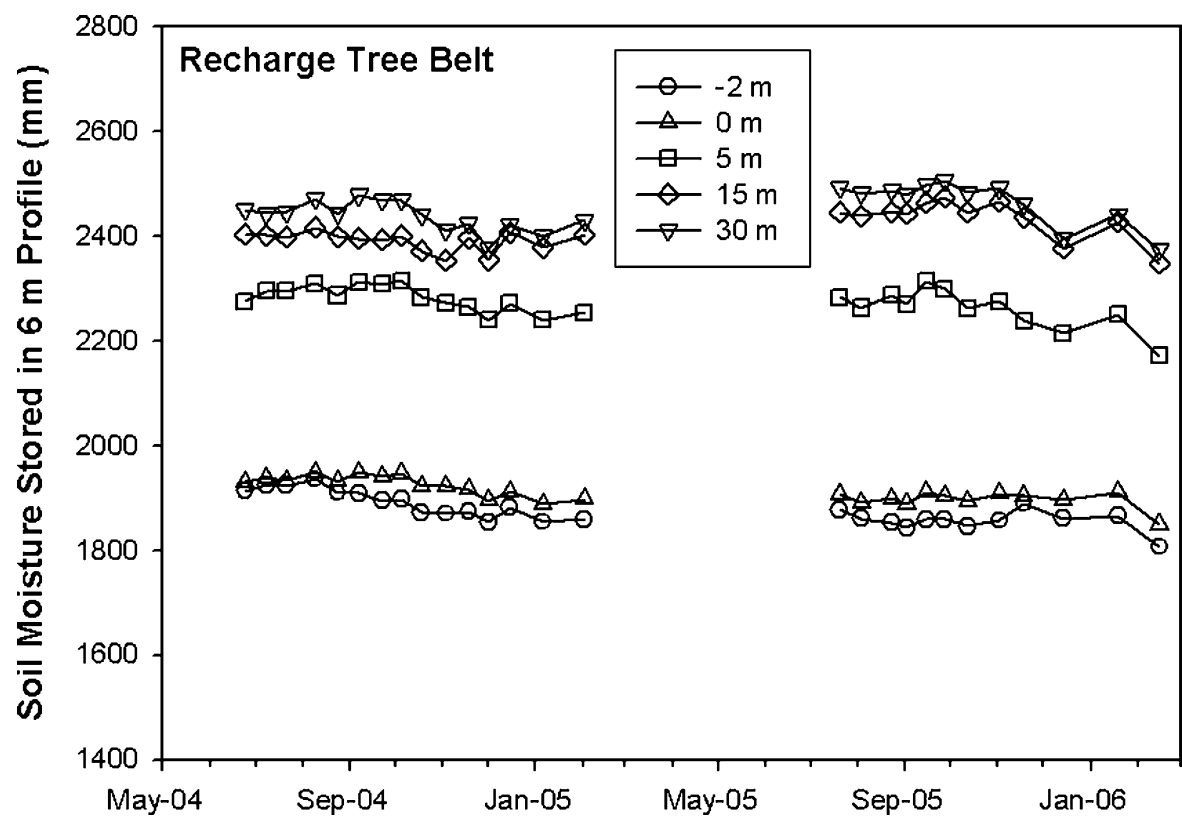


Fig. 7 Stored soil moisture in profile at the discharge tree belt site measured in a transect perpendicular to the tree belt. Data is displayed as the mean of three replicates at each distance from the dripline

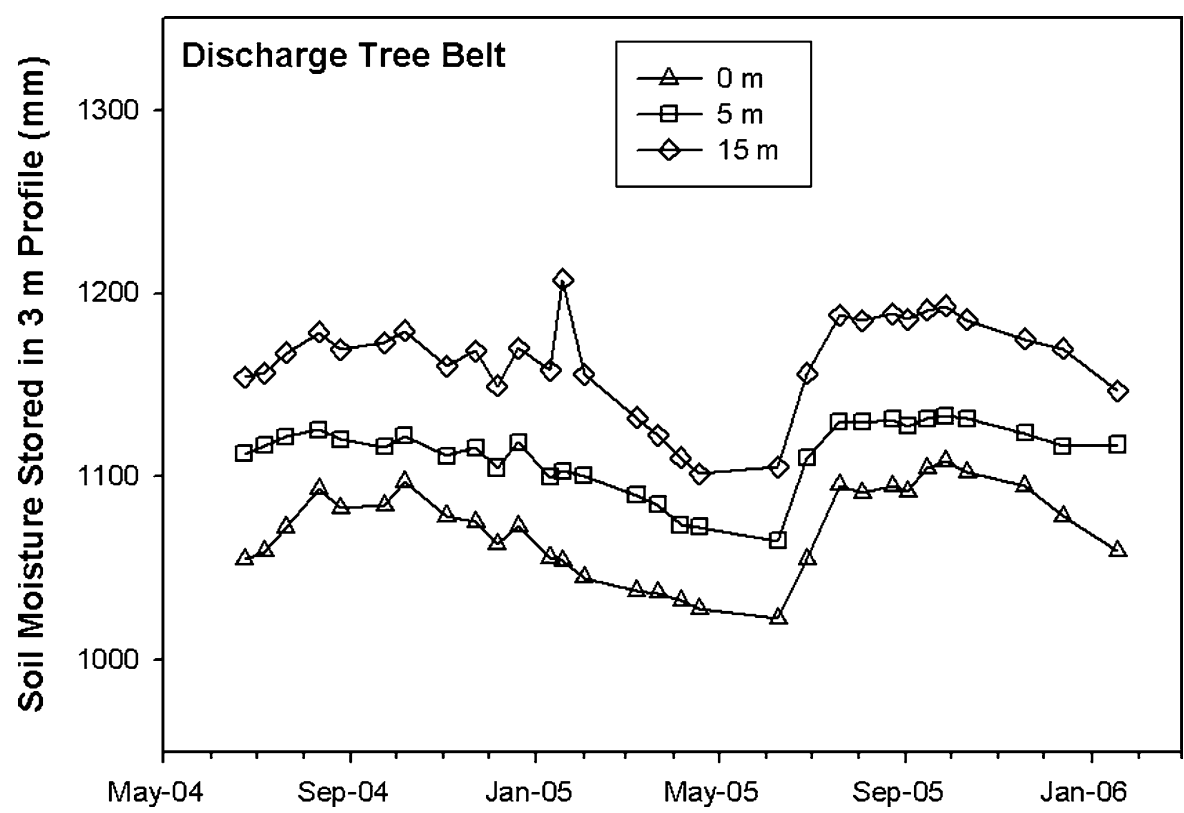

significantly different from each other. This gave three distinct soil moisture zones: beneath the trees (at -2 and $0 \mathrm{~m}$ ); in the mixture zone between the trees and the pasture (at $5 \mathrm{~m}$ ); and, the pasture zone (at 15 and $30 \mathrm{~m}$ ). The discharge tree belt followed the same pattern as the recharge tree belt except that there was less difference between the stored soil moisture at 0 and $15 \mathrm{~m}$ - they are not significantly $(P>0.05)$ different from each other.
For both the tree belts, the difference in stored soil moisture between the pasture and each measuring point was fitted to Eq. 2 using a least squares regression. This allowed the equivalent width of the tree belt to be found using Eq. 5 (Fig. 8). An increasing trend with time was present in the equivalent width estimates for both tree belts. Since trees grow over time it is not unexpected that they would also increase the area that they hydrologically occupy over time.
Fig. 8 Equivalent width of each tree belt to be added to the width from dripline to dripline. The solid lines represent the line of best fit through all of the data for each tree belt; the dashed line represents the line of best fit for the discharge tree belt only for the data from March to July. This was the time of year when the groundwater level was at its lowest, and therefore the influence of the groundwater upon the soil moisture should be minimised and the influence of the trees upon the soil moisture storage should be greatest

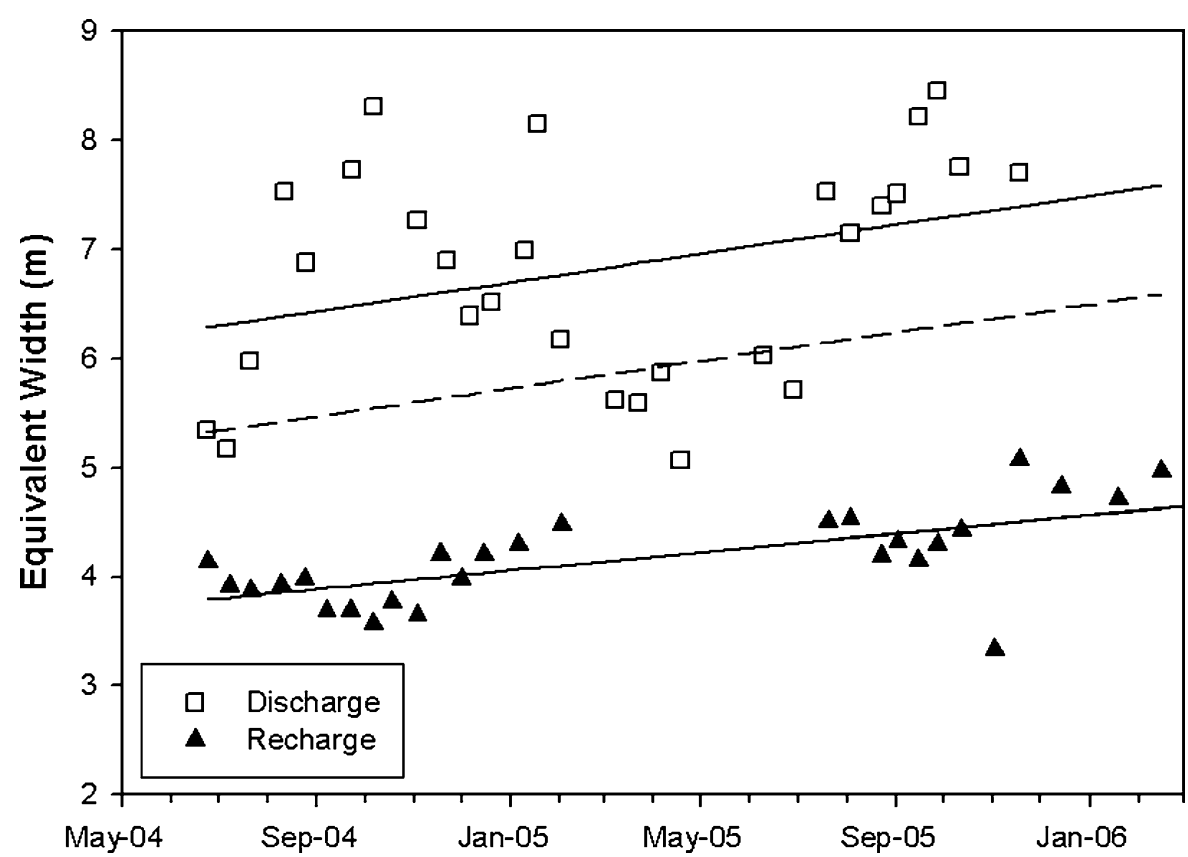


Fig. 9 Areal transpiration for each tree belt
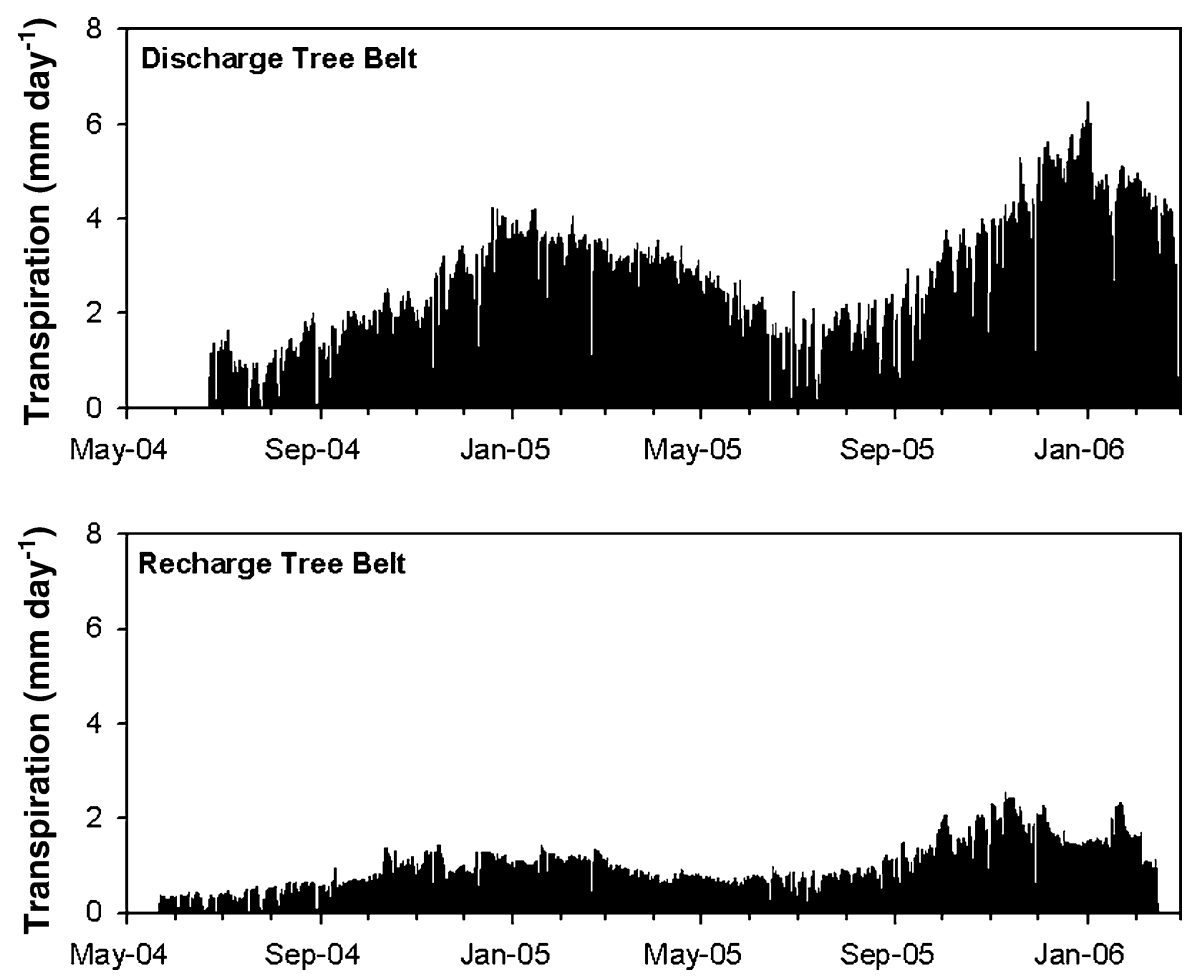

There was also an apparent seasonal trend in the equivalent width time series at each tree belt. This was consistent with the pulsating influence domain of Ecological Field Theory (Walker et al. 1989). The seasonal trend was out of phase between the recharge and discharge tree belt; this has not been investigated further here.

\section{Areal transpiration}

The volumetric transpiration of the surveyed length of each tree belt (Fig. 5) was divided by the effective width of the tree belt multiplied by the surveyed length to get the areal transpiration rate in $1 \mathrm{~m}^{-2}$ day ${ }^{-1}$ or equivalently $\mathrm{mm} \mathrm{day}^{-1}$ (Fig. 9). At this field site the discharge tree belt has transpired much more water on an areal basis than the recharge tree belt.

\section{Discussion}

A comparison between crown projected area and effective width for up scaling volumetric transpiration to areal transpiration has found that the areal transpiration calculated on the basis of the crown projected area was approximately double the transpiration calculated using the effective width concept (Fig. 10).

In a water-limited environment, such as the recharge tree belt, transpiration calculated using

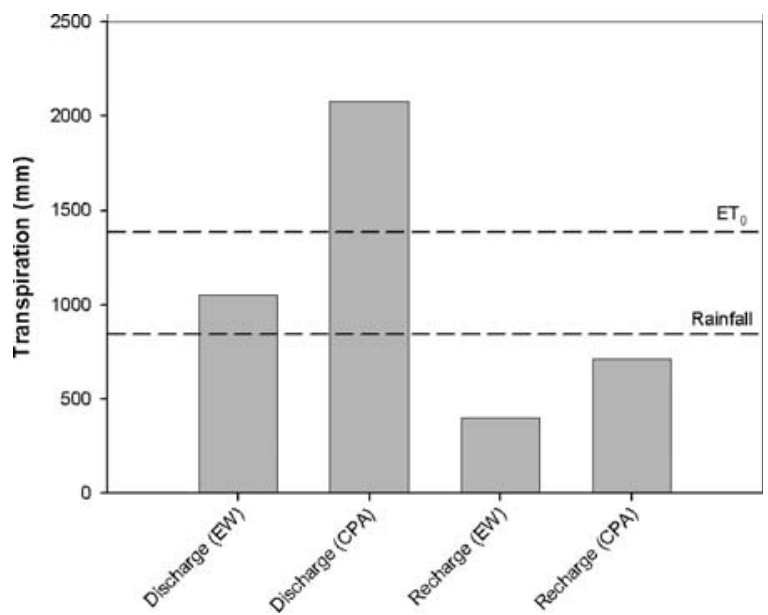

Fig. 10 Comparison in areal transpiration for the calendar year 2005 for the recharge and discharge tree belts using the crown projected area $(C P A)$ and effective width $(E W)$ methodologies for upscaling. Rainfall and $\mathrm{ET}_{\mathrm{o}}$ for 2005 are shown for reference 
the crown projected area will be an over estimate. This suggests that the trees are using all the available water, thus implying that recharge and runoff are negligible. The results shown in Fig. 10 do not include interception or soil evaporation and when these quantities are added, the total ET will actually exceed rainfall suggesting that the tree belt has another source of water. In catchments affected by dryland salinity, such as Brays Flat, trees are often used to reduce recharge and runoff with the aim of minimising salt discharge to land and stream. Our data suggests that if areal transpiration is calculated on the basis of crown projected area then the benefits of the tree belt may be grossly overstated.

Using the crown projected area as the basis for upscaling in an energy-limited environment would give results that are infeasible. The calculated transpiration for the discharge tree belt would be $700 \mathrm{~mm}$ above $\mathrm{ET}_{\mathrm{o}}$, and this does not include further losses to the atmosphere through interception, bare soil evaporation or understorey transpiration (Fig. 10). While transpiration rates greater than $\mathrm{ET}_{\mathrm{o}}$ may be possible for a tree belt due to the increased light interception (Smith et al. 1997) and the advection and entrainment of sensible heat (Smith et al. 1997; Taylor et al. 2001), a crop co-efficient approaching 2.0 seems highly unlikely. In a review of Western Australian research, Raper (1998) calculated a crop co-efficient of 1.5 for plantation E. cladocalyx and E. globulus reported by Greenwood et al. (1985), however, doubts were expressed over the methodology used in the calculation of ET. In a very detailed study, Benyon et al. (2006) showed that in a climate similar to Brays Flat, trees can use water at rates of double rainfall but the crop co-efficients were only just greater than 1 (1.01 E. globulus, 1.09 P. radiata, 1.00 C. maculata).

Using the crown projected area as the basis for upscaling volumetric transpiration to areal transpiration will result in a gross over-estimation of transpiration leading to significant errors in water balance calculations. The method presented in this paper shows the calculated areal transpiration was between rainfall and $\mathrm{ET}_{\mathrm{o}}$. Once the other elements of the water balance are added, the total ET should be quite close to the calculated potential. This would be the expected result in an environment with an infinite source of water (on the time scale of the measurements) within $1.5 \mathrm{~m}$ of the ground surface.
Acknowledgements The authors wish to thank $\mathrm{R}$ and $\mathrm{R}$ McKay for access to their property on which this research was conducted. This paper was the result of a collaboration between three projects: The integration of woody and herbaceous perennials funded by the CRC for Plant Based Management of Dryland Salinity; Key Sites for Hydrology, Salinity and Model Validation funded by the NSW Salinity Strategy and the National Action Plan for Salinity and Water Quality; and, Sustainable Grazing on Saline Lands funded by Land Water and Wool; an initiative of Australian Wool Innovation and Land and Water Australia.

\section{References}

Benyon RG, Theiveyanathan S, Doody TM (2006) Impacts of tree plantations on groundwater in south-eastern Australia. Aust J Bot 54:181-192

Cermák J, Hruska J, Martinková M, Prax A (2000) Urban tree root systems and their survival near houses analyzed using ground penetrating radar and sap flow techniques. Plant Soil 219:103-116

Cermak J, Kucera J and Nadezhdina N (2004) Sap flow measurements with some thermodynamic methods, flow integration within trees and scaling up from sample trees to entire forest stands. Trees-Struct Funct 18:529-546

David TS, Ferreira MI, Cohen S, Pereira JS, David JS (2004) Constraints on transpiration from an evergreen oak tree in southern Portugal. Agr Forest Meteorol 122:193-205

Eagleson PS (1982) Ecological optimality in water-limited natural soil-vegetation systems. 1. Theory and hypothesis. Water Resour Res 18:325-340

Eastham J, Rose CW (1990) Tree/pasture interactions at a range of tree densities in an agroforestry experiment. I. Rooting patterns. Aust J Agric Res 41:683-695

Edwards WRN, Warwick NWM (1984) Transpiration from a kiwi fruit vine as estimated by the heat pulse technique and the Penman-Monteith equation. New Zeal J Agr Res 27:537-543

Ellis T, Hatton T, Nuberg I (2005) An ecological optimality approach for predicting deep drainage from tree belts of alley farms in water-limited environments. Agric Water Manage 75:92-116

Gerwitz A, Page ER (1974) An empirical mathematical model to describe plant root systems. J Appl Ecol 11:773-782

Granier A, Biron P, Breda N, Pontailler JY, Saugier B (1996) Transpiration of trees and forest stands: short and longterm monitoring using sapflow methods. Global Change Biol 2:265-274

Greenwood EAN, Klein L, Beresford JD, Watson GD (1985) Differences in annual evaporation between grazed pasture and Eucalyptus species in plantation on a saline farm catchment. J Hydrol 78:261-278

Hatton TJ, Vertessy RA (1990) Transpiration of plantation Pinus radiata plantation estimated by the heat pulse method and the Bowen ratio. Hydrol Process 4:289-298

Hatton TJ, Wu H-I (1995) Scaling theory to extrapolate individual tree water use to stand water use. Hydrol Process 9:527-540 
Huber B (1932) Observation and measurement of plant sapflow. Ber Deut Gessell 50:89-109

Jeffrey SJ, Carter JO, Moodie KB, Beswick AR (2001) Using spatial interpolation to construct a comprehensive archive of Australian climate data. Environ Modell Softw 16:309-330

Knight J (1999) Root distributions and water uptake patterns in Eucalypts and other species. In: Landsberg JJ (ed) The ways trees use water. RIRDC, Canberra

Landsberg JJ (1999) Tree water use and its implications in relation to agroforestry systems. In: Landsberg JJ (ed) The ways trees use water. RIRDC, Canberra

Landsberg JJ, McMurtrie R (1984) Water use by isolated trees. Agric Water Manage 8:223-242

Lefroy EC, Stirzaker RJ, Pate JS (2001) The influence of tagasaste (Chamaecytisus proliferus Link.) trees on the water balance of an alley cropping system on deep sand in south-western Australia. Aust J Agric Res 52:235-246

Monteith JL (1973) Principles of environmental physics. Edward Arnold, London, p 241

Nadezhdina N, Cermak J (2003) Instrumental methods for studies of structure and function of root systems of large trees. J Exp Bot 54:1511-1521

Oliver YM, Lefroy EC, Stirzaker RJ, Davies CL (2005) Deepdrainage control and yield: the trade-off between trees and crops in agroforestry systems in the medium to low rainfall areas of Australia. Aust J Agric Res 56:1011-1026

Raper G P (1998) Agroforestry water use in Mediterranean regions of Australia. In: Water and Salinity Issues in Agroforestry, no. 2. RIRDC, Canberra.

Schenk HJ, Jackson RB (2002) Rooting depths, lateral root spreads and below-ground/above-ground allometries of plants in water-limited ecosystems. J Ecol 90:480-494

Smith DM, Jarvis PG, Odongo JCW (1997) Energy budgets of windbreak canopies in the Sahel. Agr Forest Meteorol $86: 33-49$
Smith M, Allen RG, Monteith JL, Perrier A, Pereira LS, Segeren A (1992) Expert consultation on revision of FAO methodologies for crop water requirements. Food and Agriculture Organisation of the United Nations, Rome, p 60.

Stirzaker RJ, Lefroy EC, Ellis TW (2002) An index for quantifying the trade-off between drainage and productivity in tree-crop mixtures. Agric Water Manage 53: 187-199

Sudmeyer R (2002) Tree root morphology in alley systems. RIRDC/L\&W Australia/FWPRDC Joint Venture Agroforestry Program, Canberra, p 22

Swanson RH, Whitfield DWA (1981) A numerical analysis of heat pulse velocity theory and practice. J Exp Bot 32:221239

Taylor PJ, Nuberg IK, Hatton TJ (2001) Enhanced transpiration in response to wind effects at the edge of a blue gum (Eucalyptus globulus) plantation. Tree Physiol 21:403-408

Walker J, Dowling TI (1991) A non-stochastic, physiologically based model of plant invasion using ecological field theory. Plant Prot Quart 6:10-13

Walker J, Sharpe P J H, Penridge L K, Wu H (1989) Ecological field theory: the concept and field tests. Plant Ecol 83:81-95

White DA, Dunin FX, Turner NC, Ward BH, Galbraith JH (2002) Water use by contour-planted belts of trees comprised of four Eucalyptus species. Agric Water Manage 53:133-152

Wildy DT, Pate JS, Bartle JR (2004) Budgets of water use by Eucalyptus kochii tree belts in the semi-arid wheatbelt of Western Australia. Plant Soil 262:129-149

Zeppel MJB, Yunusa IAM, Eamus D (2006) Daily, seasonal and annual patterns of transpiration from a stand of remnant vegetation dominated by a coniferous Callitris species and a broad-leaved Eucalyptus species. Physiol Plantarum 127:413-422 